\title{
The Physicochemical Properties of Spray-Dried Papaya Leaf Powders
}

\author{
T. Anu Babu ${ }^{1}$, Sivala Kumar ${ }^{2}$, D.D. Smith $^{3}$ and R. Lakshmipathy ${ }^{4}$ \\ ${ }^{1}$ College of Agricultural Engineering, ${ }^{2}$ College of Food Science and Technology, \\ Bapatla, Andra Pradesh, India, \\ ${ }^{3}$ College of Food Science and Technology, Pulivendula, Andra Pradesh, India, \\ ${ }^{4}$ Advanced PG Centre Lam, Guntur, Andra Pradesh, India \\ *Corresponding author
}

A B S T R A C T

\section{Keywords \\ Spray drying, Papaya leaf juice, Maltodextrin concentration and Total flavonoid content \\ Article Info \\ Accepted: \\ 04 December 2018 \\ Available Online: \\ 10 January 2019}

A study was conducted using laboratory spray dryer (Lab plant SD- 05) to produce spraydried papaya leaf powders using three different maltodextrin concentrations $(8 \%, 10 \%$ \& $12 \%)$ as the encapsulating agent, three feed flow rates $(350 \mathrm{~mL} / \mathrm{h}, 475 \mathrm{~mL} / \mathrm{h}$ and 600 $\mathrm{mL} / \mathrm{h})$ and three different inlet temperatures $\left(130{ }^{\circ} \mathrm{C}, 140{ }^{\circ} \mathrm{C}\right.$ and $\left.150{ }^{\circ} \mathrm{C}\right)$. The spray-dried papaya leaf powders were analysed for moisture content, water activity, color, $\mathrm{pH}$ and total flavonoid content. Results demonstrated that as inlet air temperature increased, the moisture content, water activity and total flavonoid content decreased. However, there was no significant change in the $\mathrm{pH}$ of the spray-dried powders for all the inlet temperatures investigated. Colormetric analyses showed that the $L^{*}, a^{*}, b^{*}$, hue and chroma values changed with the inlet temperatures.

\section{Introduction}

Papaya (Carica papaya L.) belongs to the family of Caricaceae. Papaya leaves contain antioxidant compounds such as flavonoids. Flavonoid has shown to play an important role in prevention of many ill health conditions. Flavonoid from carica papaya leaves have significant anti-dengue activities (Senthilvel et al., 2013). Otsuki et al., (2010) reported that flavonoids had several functions i.e. antiinflammation, anti-tumor and anti-cancer. Papaya leaf has many benefits. In some parts of Asia, the young leaves of the papaya are steamed and eaten like spinach. Fresh, green papaya leaf is an antiseptic, while the brown, dried papaya leaf is the best as a tonic and blood purifier and carica papaya leaves extracts used to treat dengue fever in patients (Ahmad et al., 2011). Recent reports have claimed possible beneficial effects of papaya leaf juice in treating patients with dengue viral infections (Yunita et al., 2012).

The papaya leaf juice by spray drying process can produce a good quality final product with low water activity and reduce the weight, resulting in easy storage and transportation. It 
can be easily added to other foods. Thus spray drying is the best alternative to obtain colorants and natural flavouring (Langrish et al., 2009). Although spray drying of food materials are affected by several parameters but inlet air temperature, maltodextrin concentration and feed flow rate are very important parameters. Therefore, this study was conducted to examine the physicochemical properties of spray dried of papaya leaf powder.

\section{Materials and Methods}

\section{Preparation of papaya leaf juice}

Green papaya leaves of same maturity level were collected from local field, leaves were washed and sliced. The sliced leaves were again washed with mineral water. From papaya leaf slices, juice was extracted by using INTEX mixer grinder. For each experimental run, the papaya leaves $(1 \mathrm{~kg})$ was blended in distilled water $(250 \mathrm{~mL})$, in the ratio of $1: 0.25$. The juice was separated from papaya leaf waste through filtering.

\section{Preparation of spray dried papaya leaf powder}

The resulting papaya leaf juice was twice filtered using a muslin cloth to avoid blocking of the atomizer of the spray dryer. The carrier agent maltodextrin of $8 \%, 10 \%$ and $12 \% \mathrm{w} / \mathrm{v}$ was added to the papaya leaf juice to increase concentration and to reduce hygroscopicity of the dried powder. Initially papaya leaf juice has $5{ }^{\circ}$ Brix after addition of maltodextrin concentrations $8 \%, 10 \%$ and $12 \% \mathrm{w} / \mathrm{v}$, the ${ }^{\circ}$ Brix was increased to $13 \%, 15 \%$ and $17 \%$ ${ }^{\circ} \mathrm{B}$, respectively. Then the concentrated papaya leaf juice was fed in to the drying chamber with feed flow rates of $350 \mathrm{~mL} / \mathrm{h}$, $475 \mathrm{~mL} / \mathrm{h}, 600 \mathrm{~mL} / \mathrm{h}$ and inlet air temperatures were maintained at $130{ }^{\circ} \mathrm{C}, 140{ }^{\circ} \mathrm{C}$ and $150{ }^{\circ} \mathrm{C}$ temperatures. Obtained powder was stored in aluminium laminated polyethylene covers under ambient conditions.

\section{Analysis of the spray-dried powder}

The spray-dried powders were analyzed for their moisture content, water activity, color $\mathrm{pH}$ and total flavonoid content as described in Sections 2.3.1-2.3.5.

\section{Moisture content}

The moisture content was determined based on AOAC method. Triplicate samples of papaya leaf powder ( $3 \mathrm{~g}$ each) were weighed and then dried in a hot air oven at $105{ }^{\circ} \mathrm{C}$ for 3 $\mathrm{h}$. The samples were removed from the oven, cooled in a desiccator and weighed. The drying and weighing processes were repeated until constant weight were obtained.

\section{Water activity}

Measurement of water activity of papaya leaf powder was carried out using a water activity meter (Hygro Lab C1 bench-top meter). Triplicate samples were analyzed and the mean was recorded.

\section{Color measurement}

The color characteristics of the spray dried papaya leaf powder were analyzed by using Hunter Lab Colorimeter (Color Flex EZ, USA). The instrument was standardized with white and black ceramic tiles before starting the measurement. Obtained results were expressed as Hunter color values $\mathrm{L}^{*}, \mathrm{a}^{*}$ and $\mathrm{b}^{*}$ where $\mathrm{L}^{*}$ denotes lightness and darkness, $\mathrm{a}^{*}$ denotes redness and greenness and $\mathrm{b}^{*}$ denotes yellowness and blueness. Powders were packed in polyethylene covers and were measured for color characteristics. The samples were analyzed in triplicates. Color intensity in terms of chroma was calculated by the formula $\left(a^{* 2}+b^{* 2}\right)^{1 / 2}$, whereas hue angle 
$\left(\mathrm{H}^{\mathrm{o}}\right)$ was calculated by the formula $\mathrm{H}^{\mathrm{o}}=\operatorname{arc}$ $\tan \left(\mathrm{b}^{*} / \mathrm{a}^{*}\right)$. The hue values of $0^{\circ}, 90^{\circ}, 180^{\circ}$ and $270^{\circ}$ denote pure red, pure yellow, pure green and pure blue color respectively.

pH

The $\mathrm{pH}$ of the papaya leaf powder sample was determined using a $\mathrm{pH}$ meter (Systronics micro $\mathrm{pH}$ system-362, Ahmadabad, India).

\section{Total flavonoid content}

The method used for determination of total flavonoid content was adapted from Kamtekar et al., (2014). Quarcetin solution (100 mg/ml) was used to construct the standard curve. Total flavonoid content of the spray-dried papaya leaf powder was spectrophotometrically determined at $510 \mathrm{~nm}$ and the data of total flavonoids of papaya leaf powders were expressed as $\mathrm{mg}$ of quercetin equivalents/100 $\mathrm{g}$ of dry mass.

\section{Results and Discussion}

\section{Physicochemical properties of papaya leaf powder}

Table 1 shows the physicochemical properties of the papaya leaf powder used for spray drying. Hence the carrier agent maltodextrin of $8 \%, 10 \%$ and $12 \% \mathrm{w} / \mathrm{v}$ was added to the papaya leaf juice to increase concentration and to reduce hygroscopicity of the dried powder. After addition of maltodextrin of concentrations $8 \%, 10 \%$ and $12 \% \mathrm{w} / \mathrm{v}$, the ${ }^{\circ}$ Brix was increased to $13 \%, 15 \%$ and $17 \%$ ${ }^{\circ} \mathrm{B}$, respectively. Then the concentrated papaya leaf juice was spray dried by using spray dryer (Lab plant SD- 05) to obtain papaya leaf powder. Papaya leaf juice has a bright green color as indicated by the high $L^{*}$ and $-a^{*}$ values. Color measurement is an important quality indicator as it reflects the sensory attractiveness and the quality of the powders produced in spray drying process.

\section{Effect of maltodextrin}

From the observations, there was hardly any powder accumulated in the collector if maltodextrin was not added in the feed. The particles produced were very sticky and mainly deposited onto the wall of drying chamber and cyclone and could not be recovered. Therefore, maltodextrin of $8 \%$, $10 \%$ and $12 \%$ (of total feed solution) was added to the juice prior to spray drying to investigate its effect on the spray drying product. Rodriguez-Hernandez et al., (2005), Cai et al., (2000) and Desobry et al., (1997) have reported that low DE maltodextrin has better nutrient binding properties. Maltodextrin is also proved to be a very good encapsulate for low molecular weight sugars such as fructose and organic acids. Addition of $10 \%$ and $12 \%$ maltodextrin to the feed appeared to give better yield results than addition of $8 \%$ maltodextrin. These results showed that maltodextrin was a useful drying aid in spray drying of papaya leaf juice as it improved the yield of product.

Addition of maltodextrin could increase the total solid content in the feed and thus, reduce the moisture content of the product. It was suggested that maltodextrin could alter the surface stickiness of low molecular weight sugars such as glucose, sucrose and fructose and organic acids, therefore, facilitated drying and reduced the stickiness of the spray-dried product. However, if the added maltodextrin was more than $10 \%$, the resulted powders lost their attractive green color. The spray-dried powders with the addition of $8 \%, 10 \%$ and $12 \%$ maltodextrin concentrations were shown in Figure 1.

\section{Moisture content}

The results showed that the moisture content of spray dried papaya leaf powders also depends on the inlet air temperatures from 130 ${ }^{\circ} \mathrm{C}$ to $150{ }^{\circ} \mathrm{C}$. High inlet air temperatures often 
results in decrease moisture content due to the increased rate of heat transfer into the particles at higher temperatures; there was a greater driving force for moisture evaporation causing faster water removal. Similarly, moisture content of spray dried papaya leaf powders increased with increase in feed flow rates from $350 \mathrm{~mL} / \mathrm{h}$ to $600 \mathrm{~mL} / \mathrm{h}$. Higher flow rates imply shorter contact time between the feed and drying air, making the heat transfer less efficient and thus causing lower water evaporation.

The results also showed that the moisture content of the spray-dried powder decreased when the maltodextrin added increased. In a spray drying system, the water content of the feed has an effect on the final moisture content of the powder produced (Abadio et al., 2004). Addition of maltodextrin to the feed prior to spray drying increased the total solid content and reduced the amount of water for evaporation. Hence, decreased the moisture contents of the powder produced. This meant that powders with lower moisture content could be obtained by increasing the percentages of maltodextrin added.

However, if the percentages of the maltodextrin were too high, the powder produced would have lower quality because the nutrients from the papaya leaf juice would be diluted. In the case of papaya leaf juice, the green color would also loss as mentioned previously.

\section{Water activity}

Water activity $\left(\mathrm{a}_{\mathrm{w}}\right)$ is an important index for spray-dried powder because it can greatly affect the shelf life of the powder produced. Water activity of spray dried papaya leaf powder decreased with increase in the maltodextrin concentration from $8 \%$ to $12 \%$. The addition of maltodextrin could increase the total solid content in the feed and thus reduce the water activity of the product (Quek et al., 2007). Similarly water activity of spray dried papaya leaf powders increased with increase in feed flow rates from $350 \mathrm{~mL} / \mathrm{h}$ to $600 \mathrm{~mL} / \mathrm{h}$. Higher flow rates imply shorter contact time between the feed and drying air, making the heat transfer less efficient and thus causing lower water evaporation. The results also showed that water activity of spray dried papaya leaf powders also depends on inlet air temperatures from $130{ }^{\circ} \mathrm{C}$ to $150{ }^{\circ} \mathrm{C}$. High inlet air temperatures often results in decrease water activity of spray dried papaya leaf powders due to the faster heat transfer between the products and drying air resulted in more water evaporation.

\section{pH}

$\mathrm{pH}$ values of the papaya leaf powders slightly increased with increase in the concentration of maltodextrin from $8 \%$ to $12 \%$ and not affected by inlet air temperatures and feed flow rates. This finding was in agreement with the report of Gonzalez-Palomres et al., (2009) who found that $\mathrm{pH}$ of the Roselle extract powder did not change with different air drying temperatures.

\section{Color measurement}

The results of the color measurement for powders with different maltodextrin concentrations are as shown in Table 2. L* Value measures the lightness of the sample, $a^{*}$ measures the green color while $+b^{*}$ measures the yellow color. Hue angle measures the property of the color and it is the ratio of $a^{*}$ and $b^{*}$ (hue $\left.=\tan ^{-1}\left(b^{*} / a^{*}\right)\right)$. Chroma indicates the color intensity or saturation $\left(\right.$ chroma $\left.=\left(a^{* 2}+b^{* 2}\right)^{1 / 2}\right)$.

It was found that when inlet air temperature increased, the $+b^{*}$ values increased but the $-a^{*}$ values increased then decreased at $150{ }^{\circ} \mathrm{C}$. This contributed to the changes in hue angle and chroma. 
Table.1 Physicochemical properties of papaya leaf powder

\begin{tabular}{|c|c|c|c|c|c|c|c|}
\hline $\mathbf{I . A . T}$ & $\mathbf{M D C}$ & $\mathbf{F F R}$ & $\mathbf{Y}$ & $\mathbf{M . C}$ & $\mathbf{a}_{\mathbf{w}}$ & $\mathbf{p H}$ & $\mathbf{T F C}$ \\
\hline $\mathbf{1 3 0}$ & 8 & 475 & 17.8 & 4.79 & 0.34 & 6.4 & 61.83 \\
\hline $\mathbf{1 4 0}$ & 8 & 350 & 20.1 & 4.48 & 0.32 & 6.42 & 59.65 \\
\hline $\mathbf{1 4 0}$ & 8 & 600 & 14.12 & 4.95 & 0.34 & 6.39 & 58.73 \\
\hline $\mathbf{1 3 0}$ & 12 & 475 & 21.08 & 4.33 & 0.34 & 6.5 & 61.25 \\
\hline $\mathbf{1 4 0}$ & 10 & 475 & 19.72 & 4.48 & 0.33 & 6.42 & 58.39 \\
\hline $\mathbf{1 3 0}$ & 10 & 350 & 21.98 & 4.39 & 0.32 & 6.51 & 58.04 \\
\hline $\mathbf{1 4 0}$ & 10 & 475 & 19.73 & 4.49 & 0.34 & 6.43 & 53.57 \\
\hline $\mathbf{1 5 0}$ & 10 & 600 & 17 & 4.28 & 0.33 & 6.4 & 58.73 \\
\hline $\mathbf{1 5 0}$ & 10 & 350 & 22.47 & 4.16 & 0.32 & 6.42 & 59.19 \\
\hline $\mathbf{1 5 0}$ & 8 & 475 & 18.72 & 4.49 & 0.33 & 6.41 & 65.04 \\
\hline $\mathbf{1 4 0}$ & 10 & 475 & 19.71 & 4.49 & 0.34 & 6.42 & 59.65 \\
\hline $\mathbf{1 5 0}$ & 12 & 475 & 21.06 & 4.16 & 0.32 & 6.44 & 61.83 \\
\hline $\mathbf{1 3 0}$ & 10 & 600 & 16.4 & 4.79 & 0.35 & 6.48 & 59.65 \\
\hline $\mathbf{1 4 0}$ & 12 & 350 & 24.08 & 4.14 & 0.3 & 6.46 & 58.73 \\
\hline $\mathbf{1 4 0}$ & 12 & 600 & 19.21 & 4.49 & 0.34 & 6.52 & 61.25 \\
\hline $\mathbf{1 4 0}$ & 10 & 475 & 19.73 & 4.48 & 0.33 & 6.43 & 61.83 \\
\hline $\mathbf{1 4 0}$ & 10 & 475 & 19.71 & 4.49 & 0.34 & 6.42 & 59.65 \\
\hline
\end{tabular}

Table.2 Colorimetric results of the spray-dried powders

\begin{tabular}{|c|c|c|c|c|c|c|c|}
\hline I.A.T & MDC & FFR & $\mathbf{L}^{*}$ & $\mathbf{a}^{*}$ & $\mathbf{b}^{*}$ & Hue angle $\left({ }^{\circ}\right)$ & Chroma \\
\hline 130 & 8 & 475 & 51.62 & -10.02 & 35.98 & -74.87 & 37.34 \\
\hline 140 & 8 & 350 & 50.57 & -10.98 & 37.02 & -73.5 & 38.61 \\
\hline 140 & 8 & 600 & 51.72 & -10.25 & 36.19 & -74.19 & 37.61 \\
\hline 130 & 12 & 475 & 55.14 & -11.42 & 33.78 & -71.32 & 35.65 \\
\hline 140 & 10 & 475 & 53.05 & -11.41 & 36.18 & -72.51 & 37.93 \\
\hline 130 & 10 & 350 & 53.44 & -11.3 & 34.81 & -72.04 & 36.59 \\
\hline 140 & 10 & 475 & 53.09 & -11.43 & 36.22 & -72.48 & 37.98 \\
\hline 150 & 10 & 600 & 51.13 & -11.56 & 36.12 & -72.25 & 37.92 \\
\hline 150 & 10 & 350 & 50.36 & -12.06 & 37.14 & -72.04 & 39.04 \\
\hline 150 & 8 & 475 & 49.98 & -10.8 & 37.95 & -74.14 & 39.45 \\
\hline 140 & 10 & 475 & 53 & -11.45 & 36.27 & -72.47 & 38.03 \\
\hline 150 & 12 & 475 & 51.68 & -12.41 & 35.8 & -70.91 & 37.88 \\
\hline 130 & 10 & 600 & 54.86 & -10.86 & 33.69 & -72.14 & 35.39 \\
\hline 140 & 12 & 350 & 52.65 & -12.27 & 36.01 & -71.22 & 38.04 \\
\hline 140 & 12 & 600 & 54.96 & -11.54 & 35.01 & -71.78 & 36.86 \\
\hline 140 & 10 & 475 & 53.03 & -11.5 & 36.15 & -72.36 & 37.93 \\
\hline 140 & 10 & 475 & 53.07 & -11.41 & 36.19 & -72.5 & 37.94 \\
\hline
\end{tabular}


Fig.1 Spray dried papaya leaf powders with different maltodextrin concentrations

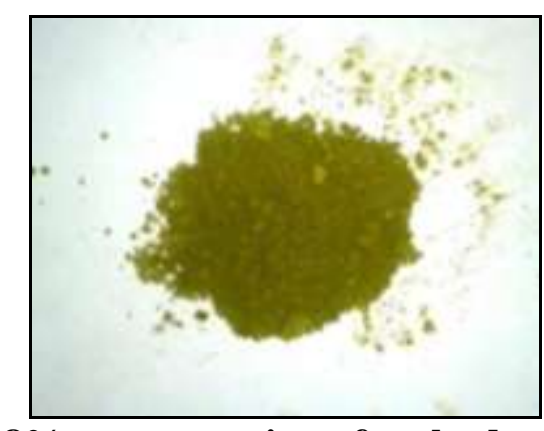

a) $8 \%$ concentration of maltodextrin

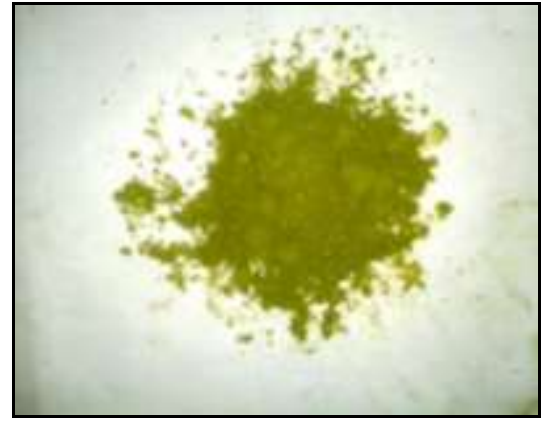

b) $10 \%$ concentration of maltodextrin

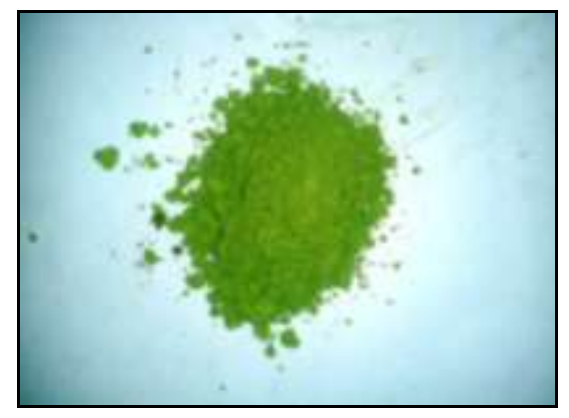

c) $12 \%$ concentration of maltodextrin

Overall, the lightness of the powders reduced and the chroma of the powders increased. This implied that the color of the powders has become darker at higher inlet air temperature. One of the explanation for this phenomenon was papaya leaf juice contains sugars which could contribute to browning of the powders at higher inlet temperature. As the inlet temperature increased, the hue angles were increased from $-74.87^{\circ}$ to $-70.91^{\circ}$. These figures are correspondent to the regions of green to yellow color where $0^{\circ}$ is pure green and $90^{\circ}$ is yellow. This meant that there was decreased in green color when inlet temperature was increased.

\section{Total flavonoid content}

Total flavonoid content decreased with increase in the concentration of carrier agent maltodextrin from $8 \%$ to $12 \%$. Vidovic et al., (2014) reported as in the case of total flavonoid was the highest in the powder obtained by adding 10\% maltodextrin as a carrier and drying agent as compared with 50\% maltodextrin. Similarly, at higher feed flow rates shorter contact between the feed and drying air making the heat transfer less efficient and thus total flavonoid content will be more. Result obtained for spray dried low fat honey based milk powder by Bansal et al., (2014). The results also showed that total flavonoid content of spray dried papaya leaf powder also depended on inlet air temperatures. As increase in the inlet air temperatures from $130{ }^{\circ} \mathrm{C}$ to $150{ }^{\circ} \mathrm{C}$ increased the loss of total flavonoid content of spray dried papaya leaf powder. Silva et al., (2011) also reported that decrease in total flavonoid content level during spray drying process.

In conclusion, maltodextrin concentration was an effective drying aid for spray drying of papaya leaf juice. Addition of maltodextrin reduced the stickiness of the products and altered the physicochemical properties of the 
spray-dried powders. The results showed that inlet temperature has great influence on the physicochemical properties of the spray-dried powders. As inlet temperature increased, the moisture content and water activity of the powders decreased. An increase in the lightness value of the powders was observed with increased maltodextrin concentration. Loss of greenness of spray dried papaya leaf powders, resulting in low $\mathrm{a}^{*} / \mathrm{b}^{*}$ value and high hue angle, increased when increased temperatures. Overall, at the inlet temperature of $130{ }^{\circ} \mathrm{C}$, the spray-dried powders have the best colorimetric results, reasonably low moisture content and water activity, as well as good total flavonoid content. Drying the papaya leaf juice above $150{ }^{\circ} \mathrm{C}$ has overall lead to inferior products due to total flavonoid content loss and changes in color. These physicochemical properties of the powders are very important to ensure the production of high quality papaya leaf powders.

\section{References}

Abadio, F.D.B., Domingues, A.M., Borges, S.V and Oliveira, V.M. 2004. Physical properties of powdered pineapple juice (Annas comosus) juice: effect of maltodextrin concentration and atomization speed. Journal of Food Engineering. 64 (3): 285-287.

Ahmad, N., Fazal, H., Ayaz, M., Abbasi, B.H., Mohammad, I and Fazal, L.2011. Dengue fever treatment with Carica papaya leaves extracts. Asian Pacific Journal of Tropical Biomedicine. 1(4): 330-333.

AOAC. 2000. Official Methods of Analysis (17th edition). Washington, DC: Assoc. of Official Analytical Chemists.

Bansal, V., Sharma, H.K and Nanda, V. 2014. Optimisation of spray drying process parameters for low-fat honey-based milk powder with antioxidant activity. International Journal of Food Science and Technology. 49: 1196-1202.

Cai Y.Z and Corke H. 2000. Production and properties of spray dried Amaranthus betacyanim pigments. J. Food Sci. 65 (6):1248-1252.

Desobry S.A, Netto F.M, Labuza T.P. 1997. Comparison of spray drying, drumdraying and freeze-drying for $b$ carotene encapsulation and preservation. J. Food Sci. 62 (6): 11581162.

Gonzalez-Palomares, S,. Estarrón-Espinosa, M., Gómez-leyva, J.F and Andrade González, I. (2009). Effect of the temperature on the spray drying of Roselle extracts (Hibiscus sabdariffa L.). Plant Foods for Human Nutrition. 64(1): 62-67. doi: 10.1007/111130-0080103-y.

Kamtekar, S., Keer, V and Pati, V. 2014. Estimation of Phenolic content, Flavonoid content, Antioxidant and Alpha amylase Inhibitory Activity of Marketed Polyherbal Formulation. Journal of Applied Pharmaceutical Science. 4 (09): 061-065.

Langrish TAG, Wang S. 2009. Crystallization rates for amorphous sucrose and lactose powders from spray drying: a comparison. Drying Technology. 27: 606-614.

Otsuki, N., Dang, N.H., Kumagai, E., Kondo, A., Iwata, S and Morimoto, C. 2010: Aqueous extract of Carica papaya leaves exhibits anti-tumor activity and immunomodulatory effects. Journal of Ethnopharmacology. 127:760-767.

Rodriguez-Hernandez. G.R,' Gonzalez'Garcia. R, Grajales-Lagunes. A, RuizCabrera.M.A.2005. Spray-drying of cactus pear juice (Opuntia streptacantha): effect on the physicochemical properties of powder and reconstituted product. Drying Technology. 23 (4):955-973.

Senthilvel, P., Lavanya, P., Kumar, K.M., 
Swetha, R., Anitha, P., Bag, S., Sarveswari, S., Vijayakumar, V., Ramaiah, S and Ambarasu, A. 2013. Flavonoid from Carica papaya inhibits NS2B-NS3 protease and prevents Dengue 2 viral assembly. Bioinformation. 9(18): 889-895.

Silva, F.C.D., Trindade, C.S.F., Alencar, S.M.D., Thomazini, $\mathrm{M}$ and Balieiro, J.C.C. 2011. Physicochemical properties, antioxidant activity and stability of spray-dried propolis. Journal of Api Product and Api Medical Science 3 (2): 94-100.
Vidovic, S.S., Vladic, J.Z., Vaštag,.Z.G., Zekovic, Z.P and Popovic, L.M. 2014. Maltodextrin as a carrier of health benefit compounds in Satureja Montana dry powder extract obtained by spray drying technique. Powder Technology. 258:209-215.

Yunita, F., Hanani, E and Kristianto, J. 2012. The effect of Carica papaya L. leaves extract capsules on platelets count and hematocrit level in dengue fever patient. International Journal of Medicine of Aromatic Plants. 2(4): 573-578.

\section{How to cite this article:}

Anu Babu, T., Sivala Kumar, D.D. Smith and Lakshmipathy, R. 2019. The Physicochemical Properties of Spray-Dried Papaya Leaf Powders Int.J.Curr.Microbiol.App.Sci. 8(01): 139-146. doi: https://doi.org/10.20546/ijcmas.2019.801.017 